\title{
EFFECTIVENESS OF ADVANCED AUTOLOGOUS PLATELET RICH FIBRIN IN THE TREATMENT OF CHRONIC PERIODONTITIS PATIENTS
}

\author{
SAmim Habeeb Ibrahim And Assist.Prof. Dr.HAShim Dawood Mousa \\ Dept. of oral and maxillofacial surgery and periodontics, College of Dentistry, University of Duhok, Kurdistan \\ Region- Iraq
}

(Accepted for Publication: August 29, 2019)

\begin{abstract}
Background and objectives: A definitive objective of periodontal treatment incorporates removing of inflammation, stopping of periodontal disease advancement and the recovery of tissues lost due to previous existing disease process. The aim of study was to examine the clinical effectiveness of advanced autologous platelet rich fibrin (A-PRF) in the treatment of moderate to severe chronic periodontitis patients using APRF with conventional open flap debridement (OFD) or OFD only without using A-PRF.

Methods: The study enlisted on 25 patients, After choice for patients who have horizontal bone loss by periapical X-ray and probing pocket $\operatorname{depth}(\geq 5 \mathrm{~mm})$. we did buccal and lingual incisions and the mucoperiosteal flaps were raised(as a conventional flap) Meticulous deformity debridement and root planning was executed by manual curette, then in test group advanced platelet rich fibrin(A-PRF)derived into the cleaned area. The same procedure used in control group but without using of A-PRF.

Results: The study groups showed significant improvement in clinical periodontal parameters of probing pocket depth (PPD) and Real attachment level (RAL) after 6 months (p-value 0.011),(p-value <0.0001) respectively, also it showed significant improvement after 3 months in RAL (P-value0.0001) and between 3 and 6 months was significant (P-value,0.002), while non-significant improvement in PPD after 3 months (Pvalue,0.446) and also non-significant in RAL through 3 and 6 months (P-value,0.123).

Conclusion: APRF was significantly improved the clinical measurements(parameters) as far as Probing pocket Depth and Clinical Attachment Level with releasing high growth factors.
\end{abstract}

KEYWORDS: periodontitis, Advanced platelet rich fibrin, periodontal pocket, openflapdebridement.

\section{INTRODUCTION}

A definitive treatment

objective involves

of periodontal stopping of periodontal disease advancement and the renewal of tissues lost due to previous-existing disease process, successful periodontal reconstruction incorporates regeneration of multiple tissues of the periodontium which regenerates at differential dimensions. The key note to periodontal recovery is to animate the progenitor cells to refill the deformity(Joseoh R.et al.,2012).

Many of techniques have been utilized for periodontal treatment, e.g. scaling ,root planning, sub gingival curettage, gingivectomy and( full open flap debridement)or split thickness flap procedures with or without osseous reshaping (Gupta M. et al.,2013).

Recently, the considerations has changed to the use of growth factors which are the biologic mediators that guide the proliferation, chemotaxis and differentiation of the locally derived progenitor cells in the deformity site(Chen., et al 2009).

However, deep periodontal pockets stay as the confounding areas for viability of treatment due to traded off debridement in areas with obliged access. (Piemontese et al.,2008).

Polypeptide growth factors (PGFs) have turned into the preferable adjunctive agents of periodontal clinicians to improve the clinical and radiological outcomes. (Piemontese et al.,2008).

A number of growth factors are built up in platelets, involving platelet-derived growth factor (PDGF) and transforming growth factor- $\beta$ (TGF$\beta)$. A convenient way to acquire autologous PDGF and TGF- $\beta$ is the use of platelet-rich plasma (PRP) (Agarwal A. and Gupta N. 2014).

Finally after presence of second generation autologous growth factors which is platelet rich fibrin (PRF) and its presentation in 2001, PRF has been mostly utilized in dentistry for several 
procedures showing its effectiveness for extraction socket management. (Aroca et al.,2009; Hoaglin and Lines,2013).

Platelet-rich fibrin (PRF) extensively used to accelerate soft and hard tissue healing, greater reduction in probing pocket depth(PPD), more CAL gain and greater intra-bony defect recovery at sites treated with PRF than the open flap debridement alone (Thorat et al.,2011).

It additionally used in intrabony deformity regeneration combined with different materials like bone graft to give a good improvements (Elgendy et al.,2015; Agarwal et al.,2016).

Since high centrifugation powers are known to move cell numbers to the base of collection tubes (whereas PRF is collected from the top one - third layer). Hence less centrifugation time would diminish cell pull-down by centrifugation powers, (Kobayashi et al., 2016;Kobayashi and Richard,.2016).

It was seen that the new sort of PRF which is called advanced platelet rich fibrin (A-PRF) released significantly higher total quantities of growth factors when compared to traditional PRF (Kobayashi E. et al.,2015).

A-PRF shows to be a perfect supplier of autologous cells (especially neutrophils and macrophages), thus empowering mutual stimulation, subsequently making a synergistic relationship in the interest of tissue recovery (Ghanaati S. et al.,2014).

However, if basically a comparable idea could be involved utilizing A-PRF, this would be exemplary for both the dental specialist and patient a similar thought could be implicated using A-PRF, this would be commendable for both the dentist and patient, therefore the present study theorized better advantages with A-PRF in the treatment of chronic periodontitis in the surgical approach. No study used A-PRF with and without sub gingival application. Therefore, the examination will endeavor to research the profitable effects of A-PRF with basic surgery for the treatment of deep periodontal pockets.

\section{The aim of study}

To explore the clinical effectiveness $\{$ plaque index (PI), modified sulcular bleeding index (SBI), probing pocket depth (PPD), real attachment level (RAL) \} of advanced autologous PRF in the treatment of moderate to severe chronic periodontitis patients using A-PRF with conventional open flap debridement (OFD) or OFD just without A-PRF.

\section{Subjects and methods}

\section{- Sample of study}

A sum of 25 non-smoking participtants, aged $32-57$, suffering from moderate to severe chronic periodontitis will enlisted for this randomized, split-mouth, controlled clinical trial of 6-month duration.

\section{- Design of study}

A randomized Clinical controlled trial comparing the effect of open flap debridement with or without using A-PRF.

\section{- The setting of the study}

Periodontal Department / College of dentistry / Duhok university

\section{- Time of study}

From :15 April / 2019 to :15 February / 2019

- Instruments, machines and Materials used for study

a. centrifuge

b. sterile plain glass-based vacuum tubes

c. UNC-15 perio- dontal probed

d. periodontal pack

e. gloves

f. masks

g. cold cure acrylic

h. plaster

i. bowel \& spatula

j. universal curette

k. Self-processing radiografing film

I. Spatula

m. plugger

n. 4-0 black silk not-absorbable surgical suture

o. 12 blade

p. Scissor

\section{- Inclusion Criteria}

a. non-smoking volunteers (males and females).

b. aged $32-57$

c. pockets $\geq 5 \mathrm{~mm}, \quad$ approximately similar radiographic bone defects $\geq 3 \mathrm{~mm}$.

d. there are no history of periodontal treatment through the past six months.

\section{- Exclusion criteria}

a. Exposed bifurcation area in molars.

b. Over growth gingiva (gingival hyperplasia).

c. Systemic diseases.

d. Patients who took chronic drug and women with pregnancy and lactation.

e. Smoking persons.

f. Diabetic patients.

g. pregnant women. 


\section{Advanced - Platelet Rich Fibrin preparation}

$10 \mathrm{ml}$ of blood was taken from each participant from venipuncture of the antecubital vein. It was poured into a sterile glass test tube $(10 \mathrm{ml})$ with no any anti-coagulant. Promptly It will centrifuged by $1500 \mathrm{rpm}$ for fourteen minutes. the absence of anticoagulants makes for a fibrin clot formation to form which can then be accumulated in the middle layer of the tube between the red layer at the base and a cellular plasma layer at the upper part of tube. (Ghanaati et al.,2014).

Following centrifugation, you can see a minimal amount of PRF with poor consistency (a cellular plasma); hence, it will be unusable. After implementing the centrifugation of the blood, we started to the removal of the result of centrifugation of whitish and yellowish color (PRF) with the use of surgical tweezers leaving behind the acellular supernatant platelet poor plasma (PPP) in the test tube, finally, the layer of PRF separated from the lower layer rich in red blood cells through the use of scissors. (Giannini et al.,2015).

\section{Procedure}

Pure clinical study was set up as a controlled randomized trail study using a split mouth design for every participant and the ethical consideration was allowed from College of Dentistry in Duhok University and written consent had taken from patient.

After selection for patients who have horizontal bone loss by periapical X-ray and probing pocket depth ( $\geq 5 \mathrm{~mm}$ ).

Firstly patients got non-surgical periodontal therapy involving of oral hygiene instruction, supra and sub gingival scaling and root planning.

After Four weeks of first phase of periodontal therapy, the base line measurements(parameters) were recorded, and it was used in the nearest millimeter.

The measurements were recorded also after three months and 6 months,at least two teeth on each side of the same patient were marked.

Twenty one of 25 preselected patients (13 females and 8males) their age was between 32-57 we exclude 4 out of preselected 25 patients, two of them were refuse to continue with the study, other one became pregnant and last one went abroad.

21 sites for test group and 21 for control group will required, the selected sides were randomly separated into experimental and control groups by using metal coin, immediately after the experimental area was anaesthetized the antecubtial veins were marked to get $10 \mathrm{ml}$ blood and transferred to the centrifuge.

We made buccal sulcular and lingual incisions and the mucoperiosteal flaps were raised (as a conventional flap), care was taken to maintain as much embrasure soft tissue as possible. Very careful and precise debridement of defect and root planning (to get clean and smooth roots)was carried out with the use of manual universal curettes also removing of granulated tissue if found from pocket inner wall and adherent tissue to alveolar bone.

Simple decortication of defected or exposed bone was performed by using sharp curette with copious normal saline irrigation.

The experimental sides will treated with autologous A-PRF, where the A-PRF will delivered in the cleaned area .PRF in the gel form was provided according to the method explained above, a part of PRF near to red layer area was cut by scissor and placed in the defected area and the remaining part of middle layer was used to prepare the A-PRF membrane which was used to cover the area as a guided tissue regeneration (GTR) A-PRFmembrane, to prevent the displacement of PRF.

The Modified vertical mattress and interrupted sutures were entered through the both sides of buccal and lingual flap before the placement of PRF in the cleaned area.

The mucoperiosteal flaps were replaced and verified in position using 4-0 not-absorbable black silk surgical suture, the protection and covering of the surgical area by using periodontal dressing for 7 days (Coe-Pak, GC America, Alsip, IL, USA). The same procedure used in control group but without using of A-PRF.

\section{Post operations care}

The participants was advised to avoid hard foods and to rinse their mouth with chlorahexidine digluconate rinses $(0.12 \%)$ tow times every day for two weeks and they were given Amoxiclav $625 \mathrm{mg}$ three times daily with profen $200 \mathrm{mg}$ tow time daily for one week.

The participants were recalled every 3 weeks to get good oral hygiene and for supragingival prophylaxis if necessary and also the same procedure was done in the control site without using advanced platelet rich fibrin, also they recalled after three months and six months to record the clinical parameters. The patients were 
advised to stay away from tooth brushing around the treated sites for a period of 7 days.

\section{Data collection}

The curable acrylic was adapted on teeth with four marked points on anterior teeth and six marked points on molars then cured by light cure. The base baseline data were recorded before treatment and at 3 months and 6 months after treatment. Clinical measurements were taken at four points around (centrals, laterals ,canine, and premolars; mesio-facial, facial, disto-facial and lingual) and six points were recorded around molars; mesio-lingual, mesio-facial, facial, disto- facial, disto-lingual and lingual. The following clinical parameters were measured: Plaque Index $(\mathrm{PI})$, modified sulcular bleeding index(mSBI), Probing Depth (PD), real Attachment Level (RAL), the (RAL) recorded from lower border of acrylic stent to the deepest area in pocket.

\section{RESULTS}

\section{Probing pocket depth}

The PPD mean of control and test group at baseline was $5.720 \pm 0.27,6.08 \pm 1.07$ at 3 months $3.91 \pm 0.46,4.06 \pm 0.70$ and at 6 months $3.58 \pm 0.45$, $3.20 \pm .53 \mathrm{~mm}$ respectively as shown in (Table 1 ).

Table (1): Comparison of mean values of PPD and CAL at baseline, 3 months and 6 months

\begin{tabular}{llll}
\hline Clinical Parameters & Control $(\mathbf{n}=\mathbf{1 8})$ & Test $\mathbf{( n = 1 8 )}$ & P-Value (Two-Sided) \\
& & \\
\hline PD & $5.720 \pm 0.27$ & $6.08 \pm 1.07$ & 0.180 \\
PD at base line & $3.91 \pm 0.46$ & $4.06 \pm 0.70$ & 0.433 \\
PD at 3 months & $3.58 \pm 0.45$ & $3.20 \pm .53$ & 0.027 \\
PD at 6 months & $4.40 \pm 1.03$ & $4.45 \pm 1.45$ & \\
Intra-Mean & & & \\
\hline RAL & $7.74 \pm 0.74$ & $8.87 \pm 1.08$ & 0.001 \\
RAL at base line & $7.04 \pm 0.80$ & $7.14 \pm 0.99$ & 0.733 \\
RAL at 3 months & $6.82 \pm 0.77$ & $6.55 \pm 1.00$ & 0.388 \\
RAL at 6 months & $5.20 \pm 0.85$ & $5.52 \pm 1.41$ & \\
Intra-Mean & &
\end{tabular}

Abbreviations: PPD (Probing Pocket Depth); CAL (Clinical Attachment Level)

Independent $t$-test was performed for all statistical analyses. The numbers are in mean $\pm S D$

\section{Real attachment level (Clinical attachment level)}

The RAL mean of control group was at base line, at three months and six months $7.74 \pm 0.74 \mathrm{~mm}$ , 7.04 \pm 0 . $\mathrm{mm}$ and $6.82 \pm 0.77 \mathrm{~mm}$ respectively.

The CAL mean of test group at base line, at three months and at six months was $8.87 \pm 1.08$ $\mathrm{mm}, 7.14 \pm 0.99 \mathrm{~mm} 6.55 \pm 1.00 \mathrm{~mm}$ respectively as shown above in (Table 1).

\section{Modified Sulcular Bleeding Index.}

The mean of mSBI score among the control treatment group. at base line, at three months and at six months was $0.90 \pm 0.30,0.69 \pm 0.23$, $0.65 \pm 0.26$ respectively.

The mean of mSBI score in the test group was at baseline ,at 3 months and at 6 months, $0.97 \pm 0.21,0.60 \pm 0.12,0.58 \pm 0.11 \mathrm{~mm}$ respectively (Table2).

Table (2): Comparison of means values of $\mathrm{mSBI}$ and PI at baseline, 3 months and 6 months

$\begin{array}{llll}\text { Clinical Parameters } & \text { Control }(n=18) & \text { Test }(n=18) & \text { P-Value (Two-Sided) }\end{array}$

\begin{tabular}{|c|c|c|c|}
\hline $\begin{array}{c}\text { mSBI } \\
\text { mSBI base line } \\
\text { mSBI } 3 \text { months } \\
\text { mSBI at } 6 \text { months } \\
\text { Intra-Mean }\end{array}$ & $\begin{array}{l}0.90 \pm 0.30 \\
0.69 \pm 0.23 \\
0.65 \pm 0.26 \\
0.75 \pm 0.28\end{array}$ & $\begin{array}{l}0.97 \pm 0.21 \\
0.60 \pm 0.12 \\
0.58 \pm 0.11 \\
0.72 \pm 0.23\end{array}$ & $\begin{array}{l}0.468 \\
0.159 \\
0.333\end{array}$ \\
\hline $\begin{array}{l}\text { PI } \\
\mathrm{Pl} \text { at base line } \\
\mathrm{Pl} \text { at } 3 \text { months } \\
\mathrm{Pl} \text { at } 6 \text { months } \\
\text { Intra-Mean }\end{array}$ & $\begin{array}{l}0.77 \pm 0.25 \\
0.56 \pm 0.14 \\
0.54 \pm 0.10 \\
0.63 \pm 0.20\end{array}$ & $\begin{array}{l}0.77 \pm 0.18 \\
0.41 \pm 0.09 \\
0.47 \pm 0.10 \\
0.55 \pm 0.20\end{array}$ & $\begin{array}{c}0.946 \\
<0.0001 \\
0.044\end{array}$ \\
\hline Inder & $\begin{array}{l}\text { PI (Plaqu } \\
\text { performe }\end{array}$ & $\begin{array}{l}\text { modified St } \\
\text { analyses. }\end{array}$ & $\pm \mathrm{SD}$ \\
\hline
\end{tabular}




\section{Plaque index}

The mean PI score at base line was $0.77 \pm 0.253$, at 3 months was $0.56 \pm 0.14$ and 6 months was $0.54 \pm 0.10$ between the control treatment group.
The mean PI score at base line was $0.77 \pm 0.18$,at 3 months was $0.41 \pm 0.09$ and at 6 months was $0.47 \pm 0.10 \quad$ (Table

Table (3): Comparison of mean changes in PPD, RAL, PI and mSBI between control and test groups

\begin{tabular}{|c|c|c|c|}
\hline \multirow[t]{2}{*}{ Changes } & \multicolumn{2}{|l|}{ Control } & \multirow[b]{2}{*}{$\begin{array}{c}\text { P-Value (Two- } \\
\text { Sided) }\end{array}$} \\
\hline & $\begin{array}{c}\text { Mean } \pm \text {. } \\
\text { Std. Deviation }\end{array}$ & $\begin{array}{c}\text { Mean } \pm \text {. } \\
\text { Std. Deviation }\end{array}$ & \\
\hline RAI (Three months from Baseline) & $-0.70 \pm 0.55$ & $-1.7 \pm 0.91$ & $<0.0001$ \\
\hline RAI (Six months from base line) & $-0.92 \pm 0.49$ & $-2.32 \pm 1.09$ & $<0.0001$ \\
\hline RAl (6 months from 3 months) & $-0.22 \pm 0.67$ & $-0.59 \pm 0.71$ & 0.123 \\
\hline Pocket (3 months from baseline) & $-1.81 \pm 0.49$ & $-2.01 \pm 1.00$ & 0.446 \\
\hline Pocket (6 months from 3 months) & $-0.33 \pm 0.49$ & $-0.86 \pm 0.45$ & 0.002 \\
\hline Pocket (6 months from baseline) & $-2.13 \pm 0.48$ & $-2.88 \pm 1.06$ & 0.011 \\
\hline mSBI (3 months from baseline) & $-0.21 \pm 0.26$ & $-0.37 \pm 0.18$ & 0.051 \\
\hline mSBI (6 months from 3 months) & $-0.04 \pm 0.15$ & $-0.018 \pm 0.09$ & 0.599 \\
\hline mSBI (6 months from baseline) & $-0.25 \pm 0.30$ & $-0.38 \pm 0.19$ & 0.131 \\
\hline PI (3 months from baseline) & $-0.21 \pm 0.22$ & $-0.36 \pm 0.19$ & 0.039 \\
\hline PI (6 months from 3 months) & $-0.03 \pm 0.15$ & $0.06 \pm 0.07$ & 0.047 \\
\hline $\mathrm{PI}$ (6 months from baseline) & $-0.24 \pm 0.26$ & $-0.30 \pm 0.19$ & 0.390 \\
\hline
\end{tabular}

Independent t-test was performed for statistical analysis.

The mean of improvement between control and test PPD group from base line to six months was statistically significant.

The mean of improvement between control and test RAL group from base line to 6 months was statistically significant (Table; 3 ).

The mean of reduction comparison in PI index between the control group and the test group at 3 months from the base line and from three months to six months statistically was significant $(\mathrm{P}>0.05)$.

The mean of reduction comparison in PI index between the control group and the test group from base line to 6 months was statistically nonsignificant $(\mathrm{P}<0.05)$ as shown in (Table. 3$)$.

The mean of reduction comparison in $\mathrm{mSBI}$ score between the control group and the test group at three months and six months from the base line also between three and six months statistically was not-significant ( $\mathrm{p}>0.05)$ (Table, 3 ).

\section{Ethical consideration}

a- Permission from college of dentistry / University of Duhok will be taken before starting.

b- Written Consent from volunteers will be taken.

\section{Data analysis methods}

The descriptive purposes of the study were presented in mean and standard deviation. The Differences of RAL, PI, mSBI, and Pocket between the control and tests at baseline, 3 months and 6 months were examined in independent $\mathrm{t}-$ test. In addition, the changes of RAL, PI, mSBI, and Pocket between control and tests at baseline, 3 months and 6 months were examined in independent t-test. The null hypothesis was rejected in a P-value of less than 0.05. The statistical calculation were performed by Statistical Package for Social Sciences version 25:00 (SPSS 25: IBM).

Analyze of data was by using of SPSS 10.5 (SPSS, Chi- cago, USA).

Descriptive statistics which included: 
- Mean

- Standard deviation

- Tables

RAL and PPD Changes were analyzed in a one-way ANOVA

\section{DISCUSSION}

Our study was designed to examine the effect of A-PRF as an adjunctive material with OFD compared with OFD only without using A-PRF for the management of chronic periodontitis pateints with horizontal bone defects.

All baseline data were recorded and compared with data results after 3 months and after 6 months.

Plaque accumulation and smoking are significant operators that were appeared to significantly influence the results of regenerative periodontal medical procedure (Agarwal et al.,2015) on the grounds that our examination avoids smokers and the patients kept up a satisfactory oral hygiene all through the investigation, in this manner, it might be expected that the cautious patient determination was additionally in charge of the positive results acquired in the two gatherings. Results of this clinical preliminary have recommended that both treatment bunches gave significant improvement in clinical parameters.

A split mouth design was chosen to avoid bias of the study because both control and test group affected by the same environment.

However, the present study on inter-group comparison, A-PRF+ OFDtreatment showed significant results in PPD and CAL.

In our study PPD reduction was $(2.14 \mathrm{~mm}$ at control group and $2.88 \mathrm{~mm}$ at test group) and CAL gain was $0.92 \mathrm{~mm}$ in control group and $2.32 \mathrm{~mm}$ in test group

The results of our study can compared with results used traditional chokrans PRF in horizontal bone defects and infrabony defects, although many studies proved that A-PRF is superior to PRF in number of growth factors.

The present study proved that its results were better than other similar studies even it was small differences of data and this may explains the activity and superiority of A-PRF Ghanaati S. et al.,(2014) found in a study comparing the histological cells between PRF and A-PRF that a higher existence of the cells in A-PRF may impact bone and soft tissue recovery

In other study done in Switzerland by Kobayashi et al., (2016) it was seen that the new definition of PRF (A-PRF) discharged fundamentally higher all out amounts of growth factors when contrasted with customary PRF.

Results of study done by joseph et al.,(2014) were in agreement with the results of our study but its Re-evaluation was at nine months(using prf in horizontal pattern bone loss) proved a significant probing depth reduction $(1.1 \pm 0.38 \mathrm{~mm}$ in control group, $1.73 \pm 0.53 \mathrm{~mm}$ in test group ,) and clinical attachment gain $(0.86 \pm 0.58 \mathrm{~mm}$ in control group, $1.7 \pm 0.52$ in test group)as compared to baseline.

In other study done in india the range results were near to our study results, the mean of PPD reductionat for control Group and test group were $1.04 \mathrm{~mm}$, and $1.58 \mathrm{~mm}$, respectively, At 9-month interval, The mean of CAL gain obtained was 0.85 $\mathrm{mm}$, and $1.5 \mathrm{~mm}$ in control Group and test group respectively, (Debnath K.and Chatterjee A. ,2018).

The mean of CAL gain of test group in our study was better by $0.82 \mathrm{~mm}$ than Indian test study and this may be due to the small size of sample ( 8 participant), little 5 milliliter blood for prf preparation, and it doesn't use stent guide to record its parameters.

The present study is very different in range results with a study done in turkey, the mean PPD reduction $(\mathrm{mm})$ at control group (OFD)3.01 \pm 0.84 and in test group (OFD+T-PRF) $4.13 \pm 1.06$ and RAL gain $(\mathrm{mm})$ at control group $2.31 \pm 0.73$ and at test group $3.65 \pm 1.09$ (Taner.2017) and this different between the two study ranges may because the last study selected patients with slight to moderate horizontal bone loss (not absolutely horizontal bone loss).The present study findings were completely different when compared with studies managed infrabony defects (vertical bone loss) because bone pattern has a huge effect in the final improvement.

In a study using PRF to treat the three walls intrabony defects had shown an increase in reduction of pocket depth and clinical attachment level gain of about (Mean reduction of PD and CAL gain was greater in PRF $(3.77+1.19 \mathrm{~mm}$, $3.17+1.29 \mathrm{~mm})$ than prp group $(3.77+1.07 \mathrm{~mm}$, $2.93+1.08 \mathrm{~mm}$ ) (Pradeep et al,2012)

the clinical effectiveness of autologous PRF in the treatment of intra-bony deformity of chronic 
periodontitis patients which showed reduction in Mean PD $(3.56+0.27,, 4.56+0.37>)$ and CAL gain $(2.13+0.43>3.69+0.44)$ in test group (throat.,2011) platelet-rich fibrin turned out to be successful as a sole regenerative material for treatment of intrabony deformity, in mix with OFD. (Panda., et al 2014).

\section{CONCLUSION}

APRF was significantly improved the clinical measurements in regards to Probing Pocket Depth and Clinical Attachment Level with discharging high growth factors.

\section{Recommendations}

More research work is warranted in a larger sample size with long time waiting for reevaluations of periodontal parameters.

\section{REFERENCES}

- Agarwal A, Gupta ND, Jain A. (2016) Platelet rich fibrin combined with decalcified freeze-dried bone allograft for the treatment of human intrabony periodontal defects: a randomized split mouth clinical trial. Acta odontologica Scandinavica:74:36-43

- Agarwal P, Chatterjee A, Gokhale S, Singh HP, Kandwal A. (2016) Evaluation of platelet-rich plasma alone or in combination with demineralized freeze dried bone allograft in treatment of periodontal infrabony defects:A comparative clinical trial. $J$ Indian Soc Periodontol;20:42-7.

- Aroca S, Keglevich T, Barbieri B, Gera I, Etienne D. (2009) Clinical evaluation of a modified coronally advanced flap alone or in combination with a platelet-rich fibrin membrane for the treatment of adjacent multiple gingival recessions: a 6-month study. Journal of periodontology; (80):244-252-1111

- Ashish Agarwal and Narinder Dev Gupta, (2014) Platelet-rich Plasma with Scaling and Root Planning: A Double-blind Split-mouth Randomized Study, J Periodontol Implant Dent;6(2):35-39

- Ashish Agarwal1, Narinder Dev Gupta2 \& Avikal Jain1(2015) Platelet rich fibrincombined with decalcified freeze-dried bone allograft for the treatment of human intrabony periodontal defects: a randomized split mouth clinical trial, Acta Odontologica Scandinavica.1-8

- Bielecki T, Dohan Ehrenfest DM, Everts PA, Wiczkowski A. (2012) The role of leukocytes from L-PRP/L- PRF in wound healing and immune defense: new perspectives. Current pharmaceutical biotechnology; 13:1153-1162.
- Chen FM, Shelton RM, Jin Y, Chapple IL.( 2009) Localized delivery of growth factors for periodontal tissue regeneration: role, strategies, and perspectives, Med Res Rev May; 29(3):472513.

- David M.Dohan ehrenfest,Lars Rasmusson,Tomas alberktson,(2009) Classification of platelet concentrates: from pure platelet-rich plasma (P$\mathrm{PRP}$ ) to leucocyte- and platelet-rich fibrin (LPRF).Trends in biotechnology,27(3)PP.158-167.

- Dr. A R Pradeep MDS, Dr. Nishanth S. Rao BDS, (MDS), Dr. Esha Agarwal BDS, (MDS), Dr. Pavan Bajaj BDS, (MDS)(2012) Comparative Evaluation of Autologous Platelet rich fibrin and Platelet rich plasma- in treatment of three wall intrabony pocket in Chronic Periodontitis: A Randomized Controlled Clinical Trial. Journal of Periodontology.

- Eizaburo Kobayashi1, 3 \& Laura Flückiger 2 \& Masako Fujioka-Kobayashi1,4 \& Kosaku Sawada1,3 \& Anton Sculean2 \& Benoit Schaller1 \& Richard J. Miron2 (2015) Comparative release of growth factors from PRP,PRF, andadvanced-PRF. Clin Oral Inves DOI 10.1007/s00784-016-1719-1.

- Elgendy EA, Abo Shady TE. (2015) Clinical and radiographic evaluation of Nano crystalline hydroxyapatite with or without platelet-rich fibrin membrane in the treatment of periodontal intrabony defects. Journal of Indian Society of Periodontology;19:61-65.

- Ghanaati S, Booms P, Orlowska A, Kubesch A, Lorenz J, Rutkowski J, Landes C, Sader R, Kirkpatrick C, Choukroun J (2014) Advanced platelet-rich fibrin: a new concept for cell-based S.

- Giannini1, a. cielo1, 1. bonanome1, c. rastelli2, c. derla1, f. corpaci1, g. falisi2.(2015) comparison between prp, prgf and prf: lights and shadows in three similar but different protocols 19;927-93.

- He, L., Lin, Y., Hu, X., Zhang, Y. \& Wu, H. (2009) A comparative study of platelet-rich fibrin (PRF) and platelet-rich plasma (PRP) on the effect of proliferation and differentiation of rat osteoblasts in vitro. Oral Surgery, Oral Medicine, Oral Pathology, Oral Radiology and Endodontics 108, 707-713.

- Hoaglin DR, Lines GK. (2013) Prevention of localized osteitis in mandibular third-molar sites using platelet- rich fibrin. International journal of dentistry;:875380. gingival recessions

- Jayakumar A, Rohini S, Naveen A, Haritha A, Reddy K.( 2010) Horizontal alveolar bone loss: A periodontal orphan. $J$ Indian Soc Periodontol.;14:181-5. 
- Joseph RA. (2014)Autologous platelet rich fibrin in regenerative periodontal therapy. J Clin Diagn Res.;8:PP.43-7.

- Kobayashi E, Fluckiger L, Fujioka-Kobayashi M, et al. (2016) Comparative release of growth factors from PRP, PRF, and advanced-PRF. Clinical oral investigations.

- Koel Debnath and Anirban Chatterjee (2018) A randomized comparative clinical study Treatment of horizontal defect with and without platelet-rich fibrin matrix: $J$ Indian Soc Periodontol. 22(5): 406-413

- Lindhe J, Westfelt E, Nyman S, Socransky SS, Haffajee AD.(1984) Long-term effect of surgical/non-surgical treatment of perio- dental disease. J Clin Periodontol;11:448-58.

- M Gupta, AK Lamba, M Verma, F Faraz, S Tandon, K Chawla, DK Koli (2013), Comparison of periodontal open flap debridement versus closed debridement with Er,Cr:YSGG laser , Australian Dental Journal; 58: $41-49$

- MasakoFujioka-Kobayashi and RichardJ (2016) Optimized Platelet Rich Fibrin With the Low Speed Concept: Growth Factor Release, Biocompatibility and Cellular Response, Journal of Periodontology ; 10.1902.160443

- Medina-Porqueres I, Alvarez-Juarez P. (2016) The Efficacy of Platelet-Rich Plasma Injection in the Management of Hip Osteoarthritis: A Systematic Review Protocol. Musculoskeletal care ;14(2):121-5

- N.Rosamma joseph, Arun Raghunath, Nitin Sharma, (2012) clinical effectiveness of autologous platelet rich fibrin in the management of infrabony pocket defects,Singapore Dental journal; 33:5-12

- Panda S, Doraiswamy J, Malaiappan S, Varghese SS, Del Fabbro M. (2014)Additive effect of autologous platelet concentrates in treatment of intrabony defects: a systematic review and metaanalysis. Journal of investigative and clinical dentistry, 5 PP.1-14

- Piemontese M, Aspriello SD, Rubini C, Ferrante L, Procaccini M. (2008)Treatment of periodontal intrabony defects with demineralized freezedried bone allograft in combination with platelet-rich plasma: a comparative clinical trial. J Periodontol;79:802-10.

- Shahram Ghanaati et al.,(2014),Advanced PlateletRich Fibrin: A New Concept for Cell-Based Tissue Engineering by Means of Inflammatory Cells.. Journal of Oral Implant ology 679-89

- Shahram Ghanaati,2 Patrick Booms, Anna Orlowska, Alica Kubesch, Jonas Lorenz, Jim Rutkowski, Constantin Landes ,Robert Sader, CJ Kirkpatrick, Joseph Choukroun, (2014) Advanced Platelet Rich Fibrin: A new Concept for Cell Based Tissue Engineering by Means of Inflammatory Cells, Journal of Oral Implant ology.

- Thorat MK, Pradeep AR, Pallavi B. (2011) Clinical effect of autologous platelet-rich fibrin in the treatment of intra-bony defects: a controlled clinical trial. J Clin Periodontol; 38: 925-932. 


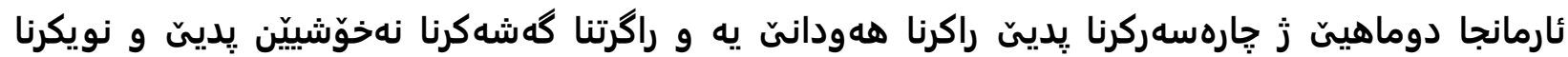

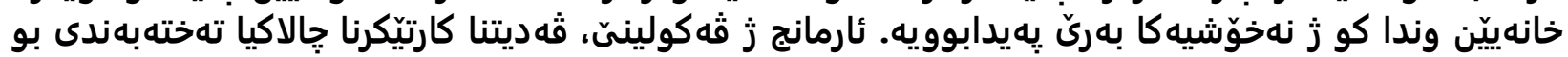

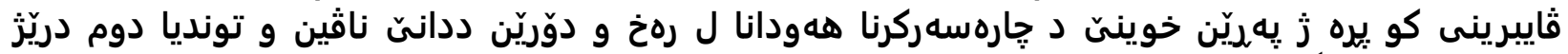

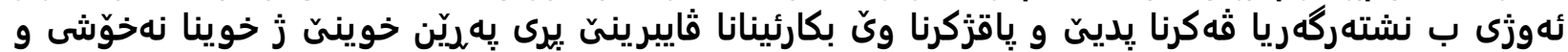

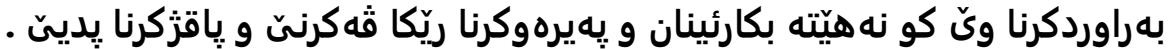

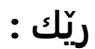

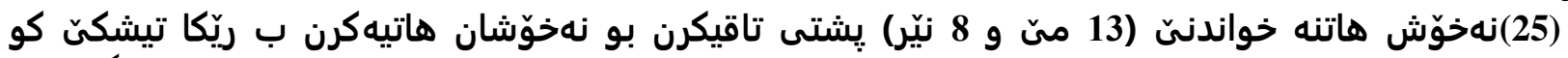

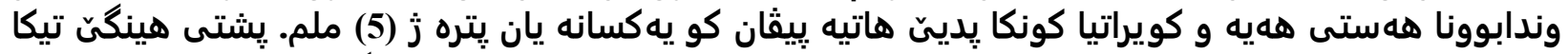

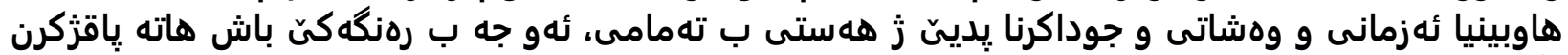

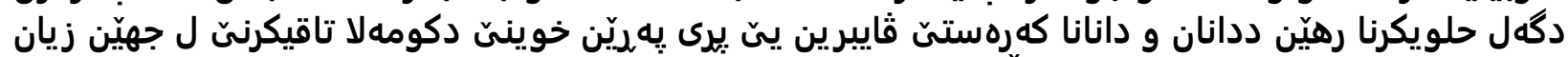

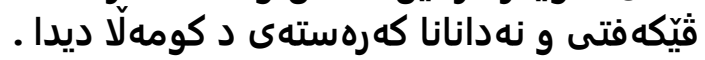

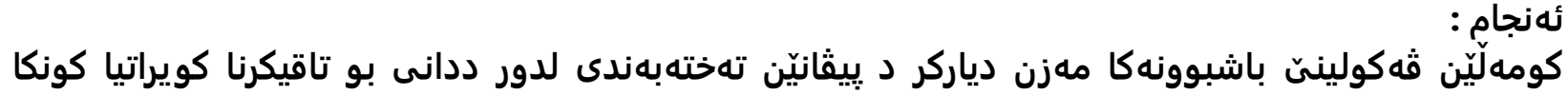

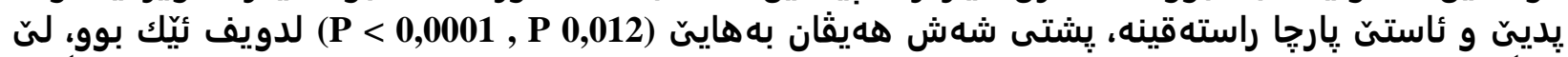

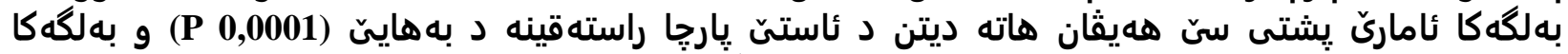

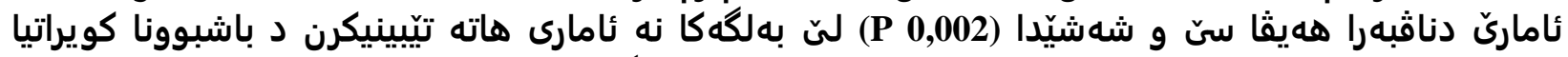

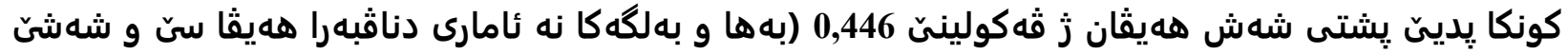

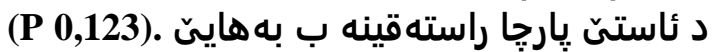

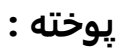

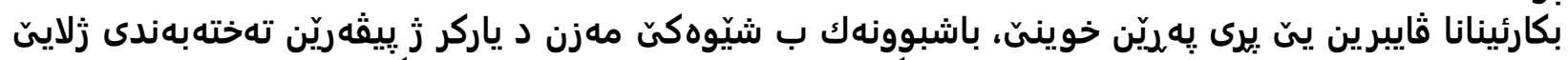

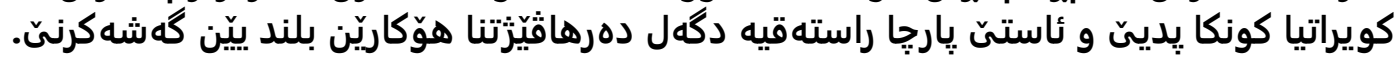

المقدمة والأهداف: الهدف النهائي من العلاج اللثوي يشمل إزالة الالتهاب ، والتوقف عن تطور

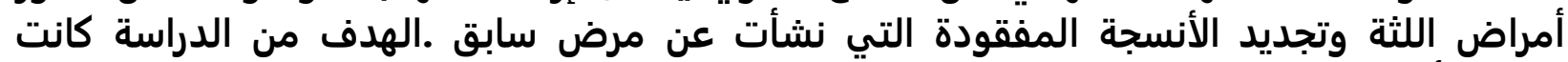

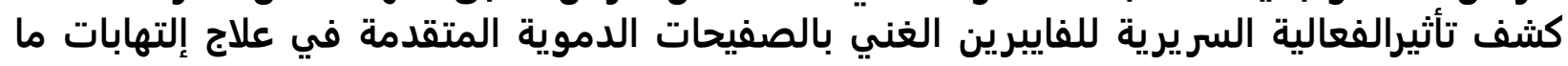


حول السن الوسطة والشديدة المزمنة بعملية فتح اللثة وتنضيفها وإستخدام الفايبرين الغني

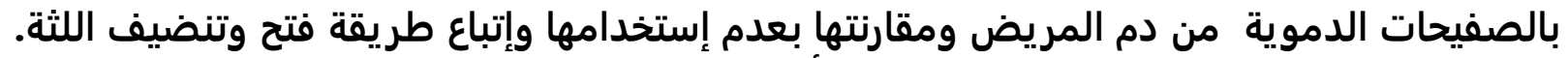

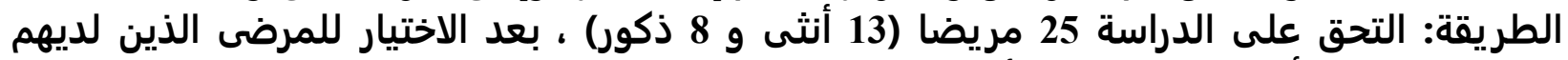

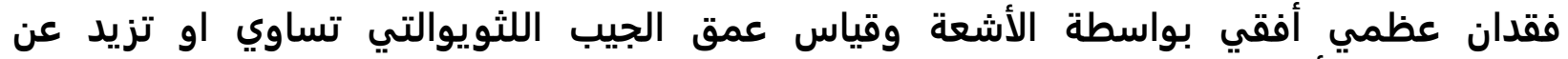

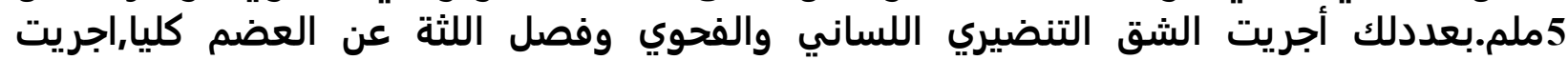

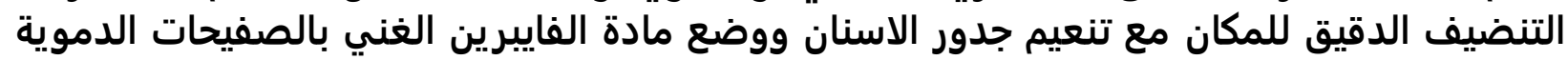

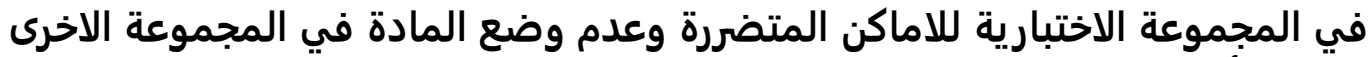

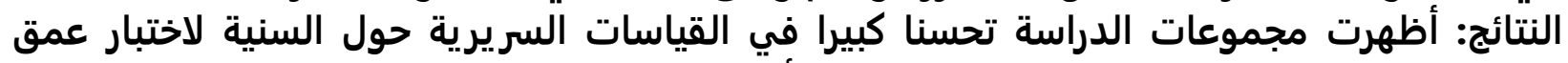

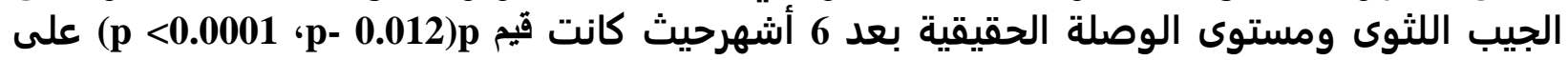

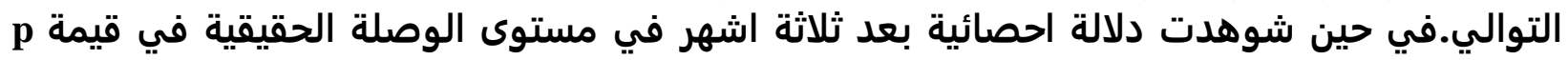

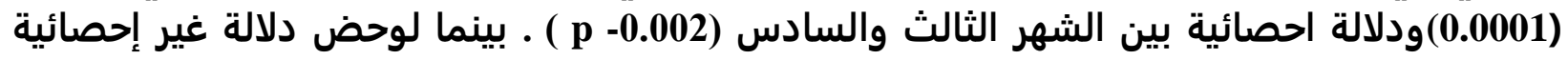

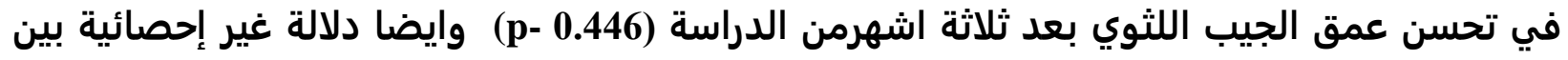

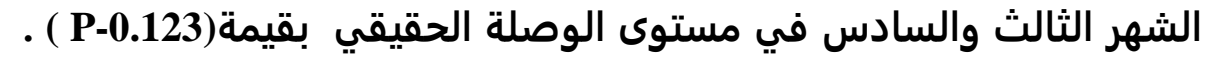

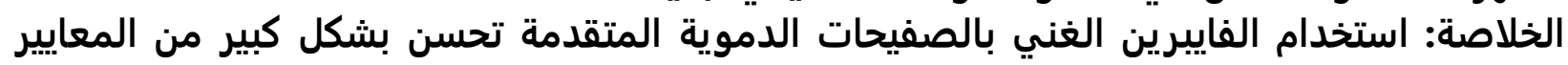

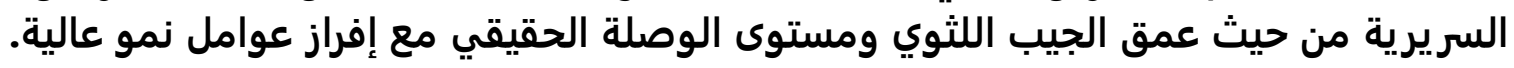

